\title{
Síntese da história da publicística: estágios reflexivos da ciência da comunicação pública alemã
}

\author{
Fábio da Silva Gomes' \\ https://orcid.org/0000-0001-9163-9472 \\ I - PUC-SP \\ São Paulo (SP). Brasil
}

\author{
RÜDIGER, F. Síntese de história da \\ publicística - estágios reflexivos da \\ ciência da comunicação pública. \\ Florianópolis, Insular, 2019, 200 p.
}

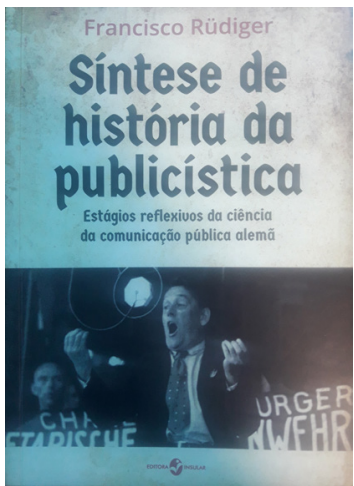

Resumo: A obra analisa a evolução dos estudos da comunicação alemã em linha com os fatos históricos do país no Século XX. Dos objetivos doutrinários, passando pelas pretensões autoritárias do regime nazista, ao papel regulador dos estudos da comunicação - o livro descreve a evolução das contribuições acadêmicas em face das mudanças comportamentais e políticas que regeram o período retratado. A resenha descreve também a destacada influência empirista norte-americana nas variadas abordagens teóricas que formam a história da publicística alemã enunciada pelo livro.

Palavras-chave: comunicação; publicística; Alemanha.

Abstract: Synthesis of publicist history: reflective stages of the German public communication science - The book analyzes the evolution of the studies of German communication in line with the historical facts of the country in the twentieth century. From doctrinal objectives, going through the authoritarian pretensions of the Nazi regime, to the regulation role of the communication study - the book describes the evolution of scholar contributions in view of the behavioral and political changes that ruled the period portrayed. The review also describes the distinctive North American empirical influence in the various theoretical approaches that form German journalism in human history, expounded by the book.

Keywords: communication; publicist; Germany. 
Francisco Rüdiger é doutor em Ciências Sociais pela USP, mestre em Filosofia pela UFRGS e professor do programa de pós-graduação em comunicação da PUC de Porto Alegre, com robusta contribuição para o campo da Comunicação. Em Síntese de história da publicística - estágios reflexivos da ciência da comunicação pública alemã apresenta o desenvolvimento dos estudos da comunicação na Alemanha com a história do país como pano de fundo.

Rüdiger parte das transformações políticas, tecnológicas e comportamentais da Alemanha no século XIX para descrever a evolução dos estudos da comunicação. Após longo período bélico, de unificação e formação do império em 1871, a Alemanha prosperou na cadência da Belle Époque (1871 e 1914) europeia. Com esse pano de fundo, Rüdiger apresenta a passagem da produção literária artesanal ao trabalho jornalístico profissional. O autor descreve o novo fazer da imprensa, que chamou a atenção de intelectuais alemães, sobretudo pelas tarefas ideológicas de dominação e as denúncias de "mau uso ideológico" dos meios de comunicação, em um enfraquecimento da soberania aristocrática e burguesa, e a formação de uma audiência homogênea e cosmopolita. Da dissolução do Império em 1918 com a proclamação da República alemã (República de Weimar), passando pelo regime nazista (1933-1945), expõe a história da publicística alemã até os anos 1970.

Rüdiger apresenta a tradição idealista alemã como definidora das reflexões teóricas acerca da relação da imprensa com a opinião pública. A tradição tem raízes no Idealismo Alemão (1781-1831) e protagonismo de Kant e Hegel. De um lado, o autor ressalta o surgimento da "figura burguesa" na opinião pública por influência da perspectiva hegeliana do saber (absoluto), da consciência holística e reflexiva germânica em oposição às ideias liberais. Por outro, a influência do imanentismo na perspectiva de enunciadores do pensamento publicístico, que defendiam a tese de que o compartilhamento de um único e mesmo espírito limitava as intenções das forças setoriais em formar a opinião pública. O autor contextualiza historicamente e organiza a obra em dez capítulos e oito estágios reflexivos destacados a seguir.

Primeiro Estágio. No período compreendido entre 1914 e 1922, Rüdiger pontua a polarização de pensadores alemães sobre o papel da imprensa e a relação com a opinião pública. O autor apresenta como destaque do período, de um lado, o jornalista austríaco Wilhelm Bauer (1888-1953), representante da perspectiva que entende a imprensa como formadora da opinião pública. De outro, Ferdinand Tönnies (1855-1936), defensor do protagonismo da opinião pública, sem relação instrumental com a imprensa. O autor retrata esse período como nascedouro de fortes grupos de comunicação, o que intensificou a produção intelectual pela manifestação prática do fenômeno observado.

Segundo Estágio. O autor caracteriza os anos 1920 como período em que o tecnicismo impactou as novas formas de comunicar. Expõe a relação de intelectuais, profissionais e homens de negócios com a perspectiva mais objetiva na formação da opinião pública - 
a "coerção tecnocrática", eivada dos conceitos da psicologia das massas de Gustav Le Bon. Rüdiger destaca três contribuições no período. Rudolf Seyffert (1893-1971) - fundador do Instituto de Pesquisa em Publicidade Comercial de Colônia (1923); Stern-Rubarth (18851972 ) - jornalista dedicado ao tema da publicidade, defensor da tese de que a bancarrota da Alemanha na Primeira Guerra Mundial fora, antes, uma derrota para a publicidade dos Aliados; Johann Plenge (1864-1963) - politólogo que migrou da esquerda socialista para o nacionalismo e dedicou-se aos temas da publicidade e da opinião pública.

Terceiro Estágio. Rüdiger apresenta o período entre 1930 a 1945 em dois capítulos. Primeiramente, o autor expõe a influência de Emil Dovifat (1890-1969), fundador da "ciência do jornal", e analisa a proposição da publicística normativa alemã de Dovifat entendimento de que os meios têm poder sobre os públicos, exercido por imposição e controle vertical da opinião. Em outro capítulo, Rüdiger expõe a publicística na Era Nazista. Narra o alinhamento de Dovifat com os propósitos nazistas por intermédio do ex-auxiliar Josef Krumback (1910-1972) - que assumiu a missão de transformar a proposição técnica da publicística normativa em tratado com fundamentação científica, o que fora rechaçado pelo regime de Hitler. Rüdiger expõe, assim, o surgimento de um novo grupo expoente nos estudos da comunicação, mais alinhados ao regime nazista. $\mathrm{O}$ autor apresenta como destaque a iniciativa de Hans Münster (1901-1963) em retomar as ideias de Krumback, propondo a publicística como ferramental prático a serviço do regime nacional-socialista. Rüdiger destaca também as contribuições de Gerhart Starke (1916-1996), que constatou que conflitos eram promovidos por influências externas ("alienígenas") na formação da opinião dos públicos sob domínio nazista. Rüdiger expõe como a contribuição de Starke promoveu os publicistas como agentes de superação das divisões internas pelos líderes nazistas.

Quarto Estágio. Os estudos da comunicação no período de pós-guerra (1945-1960) são apresentados, entre eles a publicística sistemática de Walter Hagemann e a proposta de reordenamento dos estudos da comunicação. O autor argumenta como Hagemann revitalizou as pretensões normativas e propôs o método científico da perspectiva histórica comparada, em vez de empírica, acreditando que a investigação sobre as reações do público não caberia à publicística, mas como tarefa da ciência auxiliar, a Sociologia.

Quinto Estágio. Rüdiger expõe a inserção do pensamento sociológico nos anos 1960 na nova ideia de ciência do jornal. O autor descreve o período que representou o ponto de virada no estudo da comunicação alemã, com a influência de dois importantes centros de estudos: Instituto de Pesquisa Social de Frankfurt (Escola de Frankfurt) e Instituto de Ciência de Jornal da Universidade de Munique (Escola de Munique). A Escola de Frankfurt, originada da crítica à industria cultural, que, segundo o autor, trata-se de importante tôpico da ciência social crítica (RÜDIGER, 2004), notabilizou-se pela ideia de que a opinião pública pode ser influenciada por opiniões não públicas produzidas pelos veículos de comunicação. Já a Escola de Munique dedicou-se à crítica da publicística, teorias e práticas, partindo do postulado de que as relações dialógicas entre os indivíduos e os grupos formam a essência da opinião, que formam a sociedade - e não derivada de meios técnicos manejados. 
Sexto Estágio. O autor apresenta a virada empirista dos anos 1960, que levara a publicística ao novo conceito de ciências da comunicação. Rüdiger argumenta como a influência da pesquisa em comunicação norte-americana transformou as ciências do espírito em ciências sociais empíricas. O autor destaca como Elisabeth Noelle-Neumann (1916-2010), criadora do conceito de "espiral do silêncio", liderou o movimento em defesa da reorientação epistemológica da publicística para uma abordagem multidisciplinar empirista alinhada aos estudos internacionais sobre o tema. Rüdiger destaca também a contribuição de Alphons Silbermann (1909 - 2000), fundador do European Journal of Communication (1975) e do Instituto de Estudos de Comunicação de Massa de Colônia (1973-1984), que entendia a pesquisa em comunicação como disciplina auxiliar - não obstante a valorização dos métodos empíricos e das conexões entre fenômenos de comunicação pública e interpessoal.

Sétimo Estágio. Retratando o nascimento da publicística funcional, Rüdiger registra a contribuição do holandês Henk Prakke (1900-1992), do Instituto de Munster, no período entre anos 1960 e 1970. O autor indica como Prakke elaborou a proposição da publicística aplicada/funcional: redução de pressupostos doutrinários, reforço do conceito de público participante, aplicação de estudos psicológicos e sociais como complementares.

Oitavo Estágio. O autor descreve perspectiva crítica de Harry Pross (1923-2010) nos anos 1970. O autor descreve a empreitada de Pross ao propor o retorno doutrinário da publicística à sua origem, mas com outros sentidos: emancipatório (promoção da liberdade), em vez de ideológico; reflexivo, em vez de instrumental (promoção de uma causa). É pontuado o protagonismo que Pross deu à semiótica ao propor que a formação do sentido depende da capacidade de conhecimento e reflexão, das ideias em circulação, das estruturas simbólicas hierarquizadas.

Como fruto dos estágios históricos, Rüdiger apresenta a direção epistemológica dominante da publicística: enquanto tarefa indeterminada, o estudo dos fenômenos da comunicação deveria ser tratado com abordagens multidisciplinares. O autor argumenta como a comunicação pública deixou de ser o centro das atenções, dando lugar à função reguladora. Aponta, ainda, como as reservas filosóficas da publicística foram paulatinamente esquecidas como efeito de variados fenômenos de transformação da contemporaneidade e da renovação dos estudos multidisciplinares da comunicação.

Fábio da Silva Gomes é doutorando do PPG Comunicação e Semiótica da PUC-SP. É sociólogo pela Universidade Federal de Juiz de Fora e mestre em gestão pela FGV. Tem especialização em Comunicação Política pela ECA-USP, e é membro da European Society for Opinion and Marketing Research. É autor do livro Comunicação dialógica e Reputação eleitoral: o percurso gerativo do voto.

fabiogomes@institutoinforma.com.br 


\section{Referências}

RÜDIGER, F. Síntese de história publicística - estágios reflexivos da ciência da comunicação pública alemã. Florianópolis: Insular, 2019.

Theodor Adorno e a crítica à industria cultural - Comunicação e teoria crítica da sociedade, $3^{\mathrm{a}}$ Ed. Porto Alegre: EdiPUCRS, 2004.

Resenha recebida em 01/07/2019

e aprovada em 27/07/2019. 